\title{
Treatment of metastatic pancreatic neuroendocrine tumors: relevance of ENETS 2016 guidelines
}

\author{
Margaux Foulfoin', Emmanuelle Graillot1,2, Mustapha Adham2,3, Pascal Rousset2,4, \\ Julien Forestier1, Valérie Hervieu2,5, Philip Robinson6, Jean-Yves Scoazec5, \\ Catherine Lombard-Bohas ${ }^{1}$ and Thomas Walter ${ }^{1,2}$
}

${ }^{1}$ Hospices Civils de Lyon, Hôpital Edouard Herriot, Service de Gastroentérologie et d'Oncologie Médicale, Lyon, France 2University of Lyon, Université Lyon 1, Lyon, France

${ }^{3}$ Hospices Civils de Lyon, Hôpital Edouard Herriot, Service de chirurgie, Lyon, France ${ }^{4}$ Hospices Civils de Lyon, Hôpital Edouard Herriot, Service de radiologie, Lyon, France ${ }^{5}$ Hospices Civils de Lyon, Hôpital Edouard Herriot, Service Central d'Anatomie et Cytologie Pathologiques, Lyon, France ${ }^{6}$ Hospices Civils de Lyon, DRCl, Lyon, France

Correspondence should be addressed to T Walter

Email

thomas.walter@chu-lyon.fr

\begin{abstract}
The choice of first-line treatment for metastatic pancreatic neuroendocrine tumors (mP-NET) is mainly based on prognostic factors. ENETS-2016 guidelines stratified treatment according to 3 groups: Group 1, patients in whom all lesions could be removed; Group 2, patients with Ki67 $<10 \%$, low tumor burden, no symptoms and stable disease, for whom a watch-and-wait strategy or somatostatin analogs are proposed; Group 3, symptomatic patients or with Ki67 $>10 \%$ or significant tumor burden or progressive disease, for whom a systemic chemotherapy is proposed. This retrospective study aimed to determine patient distribution, characteristics and outcome among these 3 groups. Patients with mP-NET diagnosis from 2004 to 2016 were categorized into the three groups. Prognosis was calculated using the Kaplan-Meier method. All treatments were recorded, and consistency with ENETS guidelines was explored. 104 patients were analyzed: $64 \%$ synchronous mP-NET, $80 \%$ grade 2 tumors and median overall survival (OS) of 104 (95\% Cl: 65-143) months. There were 15 patients in ENETS Group 1, 16 in Group 2 and 73 in Group 3. Median OS was not reached in Groups 1 and 2 and was 64 months (35-93) in Group 3. High liver tumor volume, high-grade tumor and progressive disease were associated with worse OS in multivariate analysis. The first-line treatment was in accordance with guidelines in $82 \% .77 \%$ percent of deceased patients received less than 4 lines of treatment. Most patients are in Group 3 and do not receive all available treatments. Thus, trials are warranted to improve first-line chemotherapy. Alternative treatments may be considered for less aggressive disease.
\end{abstract}

Key Words
- pancreas
- metastasis
- neuroendocrine tumors
- prognosis
- treatment

Endocrine-Related Cancer (2017) 24, 71-81

\section{Introduction}

The prevalence of pancreatic neuroendocrine tumors (P-NET) is 0.32 per 100,000 in the US, and the incidence is rising (Yao et al. 2008). The median survival is longer than that in pancreatic adenocarcinoma, and patients usually receive several lines of treatments. Metastases occur in $50-80 \%$ of cases, predominantly in the liver. Several treatments are now available, either loco-regional (surgery, radiofrequency ablation and liver transarterial

Published by Bioscientifica Ltd 
embolization (TAE)) or systemic (somatostatin analogs (SSA), intravenous or per OS cytotoxic chemotherapy, targeted therapy such as everolimus and sunitinib and peptide receptor radionuclide therapy (PRRT)). We now have data from phase III studies investigating SSA (Caplin et al. 2014), everolimus (Yao et al. 2011) and sunitinib (Raymond et al. 2011) in P-NET, but only in selected populations. Moreover, patients do not receive all efficient treatments in real life (Berdelou et al. 2016), and therefore, the choice of the first-line treatment is of crucial importance.

In 2016, the European Neuroendocrine Tumor Society (ENETS) (Pavel et al. 2016) and the National Comprehensive Cancer Network (https://www.nccn.org) provided a therapeutic algorithm for the management of metastatic (m) P-NET. The algorithm is based on both patient and tumor characteristics, with three main strategies: Group 1, patients in whom all lesions could be removed; Group 2, patients with Ki67 $<10 \%$, low tumor burden, no symptoms and stable disease, for whom a watch-and-wait strategy or somatostatin analogs are proposed; Group 3, symptomatic patients or with Ki67 $>10 \%$ or significant tumor burden or progressive disease, for whom a systemic chemotherapy is proposed. However, the distribution and outcomes of these three groups are unknown. Moreover, these treatment groups were defined according to prognostic factors such as symptoms, tumor grading, tumor burden, tumor growth rate (TGR) and uptake on somatostatin receptor scintigraphy (SRS), as identified from data available in the literature. This implies that mP-NET must be well characterized. However, very few studies have focused on mP-NET (Panzuto et al. 2011). Indeed, most studies have pooled either different primary tumor locations of metastatic NET (Durante et al. 2009) or poorly and well-differentiated P-NET or different stages of P-NET (Pape et al. 2008b).

Therefore, the objectives of the present study are to evaluate patient distribution and characteristics, type of first-line treatment and number of treatments received among the three groups of patients defined in ENETS guidelines. We also studied the prognostic factors of mP-NET and treatments given.

\section{Materials and methods}

\section{Population}

We retrospectively analyzed a consecutive cohort of patients with mP-NET in our institution (ENETS center of excellence) from January 2004 to July 2016. Inclusion criteria were confirmed pathological diagnosis of welldifferentiated P-NET according to the 2010 World Health Organization (WHO) criteria, and stage IV disease with synchronous or metachronous metastases. We also included patients with grade 3 P-NET, but with well-differentiated morphology as recently reported (Heetfeld et al. 2015, Coriat et al. 2016); poorly differentiated neuroendocrine carcinoma (NEC) were excluded.

The following clinical, biological and histological parameters were collected at the time of metastatic disease, either at the initial diagnosis for synchronous disease or at the first occurrence of metastases for metachronous disease: gender, age, ECOG performance status (PS), primary tumor location (head, body or tail of the pancreas), functional status, serum plasma levels of chromogranin A (CgA), serum alkaline phosphatase (ALP), liver tumor involvement, localization and number of metastatic sites, uptake on SRS or 18F-fluorodeoxyglucose positron emission tomography (FDG-PET), Ki67 index and grade. Pathological diagnosis was made or reviewed by two pathologists (V H and J-Y S) from the TENpath Network (Scoazec et al. 2016), including all G3 mP-NET. Serum levels of chromogranin A (CgA) were considered high when twice the upper limit of normal (ULN). Liver tumor involvement was categorized into two groups: $<50 \%$ and $\geq 50 \%$ of the liver as evaluated on multiphase CT scan or liver MRI. We also collected the TGR at diagnosis of metastatic disease, which was defined as 'unknown' when patients were immediately treated because of poor prognostic factors as defined in the Group 3 below, 'progressive' when patients had radiological progressive disease according to Response Evaluation Criteria in Solid Tumors (RECIST) criteria assessed by conventional imaging (CT scan or MRI) during the previous 12 months and 'stable disease' in the absence of progressive disease within the previous 12 months. By definition, patients with metachronous mP-NET were recorded as 'progressive' because of the occurrence of new metastases.

\section{Treatment groups defined in ENETS 2016 guidelines}

Patients were categorized into three groups of treatment adapted from 2016 ENETS guidelines (Pavel et al. 2016) as follows. Group 1 includes patients with mP-NET in whom all lesions, both primary and metastatic, were removed. Patients with curative surgery and/or radiofrequency ablation of all liver metastases were therefore included in this group. Group 2 includes asymptomatic patients with lowgrade (Ki67 <10\%) mP-NET, low tumor burden and stable disease or initial diagnosis (Fig. 3 of the ENETS guidelines

Published by Bioscientifica Ltd. 
(Pavel et al. 2016)). We defined the low tumor burden as a liver tumor involvement $<50 \%$ and no bone metastasis, in accordance with the French national guidelines (www. tncd.org). Group 3 includes patients with mP-NETS with Ki67 $>10 \%$ or with a high tumor liver involvement $(>50 \%)$, or the presence of bone metastasis, or progressive disease, or the presence of tumor burden-related symptoms. In these groups, according to guidelines (Pavel et al. 2016), the scheduled treatments were a watch-and-wait or SSA for Group 2 and cytotoxic chemotherapy for Group 3.

\section{Treatment}

For each systemic treatment, the presence of disease progression before treatment initiation, number of previous lines, the initiation and discontinuation dates of treatment and reason of discontinuation (defined as scheduled following the treatment plan, radiological progression according to RECIST criteria, clinical progression but without radiological progression, grade 3-5 toxicity or patient choice) were recorded. The effectiveness of each treatment was evaluated by the best response (objective response, stable disease and progressive disease) according to RECIST criteria.

\section{Statistical analysis}

Categorical variables are expressed as percentages and compared by the chi-square test or with Fisher's exact test when appropriate. Continuous variables are expressed as median and range. Overall survival (OS) was calculated from the date of metastatic diagnosis to the date of death or last follow-up. OS was estimated using the Kaplan-Meier method, and comparisons were performed using the logrank test. For continuous variables, the cut-off chosen was their median value. Only variables with a $P$ value of $<0.05$ in univariate analysis were introduced in the Cox model. Relative risks were expressed as hazard ratios (HRs) with $95 \%$ confidence intervals (CIs). A $P$ value of $<0.05$ was considered statistically significant. The cut-off date for the final analysis was July 1, 2016. All statistical analyses were performed using Statistical Package for Social Sciences, version 17.0.

\section{Results}

\section{Patient characteristics}

A total of 104 patients with mP-NET were included, 67 (64\%) had synchronous metastases (Table 1). In the
37 (36\%) patients with metachronous disease, the median time between diagnosis of the primary tumor and first occurrence of metastases was 42 (range: 5-161) months. Sixteen (15\%) had functioning mP-NET (Zollinger Elison Syndrome $n=6$, insulinoma $n=6$, VIPoma $n=2$, glucagonoma $n=1$, PTH-rp $n=2$, and Cushing syndrome $n=1$ ). Most patients had liver metastases $(94 \%)$ and $12 \%$ had bone metastases. All mP-NETs were well differentiated: $9 \%$ grade $1,77 \%$ grade 2 and $14 \%$ of grade 3 . Median Ki67 was 10\% (range: 1-60). Among those with available nuclear imaging, most cases had a positive Octreoscan $(74 / 87,85 \%)$ as was the case for FDG-PET $(26 / 32,81 \%)$. According to ENETS guidelines, 15 (15\%) were included in Group 1 and treated by complete resection, 16 (15\%) should have received watch-and-wait or SSA (Group 2) and 73 (70\%) chemotherapy (Group 3). By definition, all patients of Group 2 had no bone metastases, liver tumor burden $<50 \%$, Ki67 index $<10 \%$ and no progressive disease (Table 1). All NET-G3 (Ki67 >20\%) $(n=14)$ were by definition in Group 3. Within Group 3, the characteristics of NET-G3 were similar to those of NET-G2, except that they less often had an uptake on Octreoscan (46\% vs $88 \%$, $P=0.002$; Table 2).

\section{Overall survival and prognostic factors}

The median duration of follow-up was 31 (range: 3-140) months from the diagnosis of metastatic status. Median OS was 104 (95\% CI: 65-143) months (Fig. 1A). Five-year survival rate was $62 \%$. Median OS was not reached in Groups 1 and 2 and was 64 (95\% CI: 35-93) months in Group 3, $P<0.001$ (Fig. 1B). High liver tumor involvement, high-grade tumor and the TGR were significantly associated with a worse OS in univariate and multivariate analyses (Fig. 2A, B, C and Table 3). A cut-off at $20 \%$ for $\mathrm{Ki} 67$, but not 5\% and 10\% remained significantly associated with OS after multivariate analysis. Among the 73 patients included into Group 3, the grade, the TGR, uptake on Octreoscan, but not the liver tumor volume were associated with OS after univariate analysis (Supplementary Table 1, see section on supplementary data given at the end of this article). However, only the grade 3 and the TGR ('progressive disease' and 'unknown') remained significantly associated with worse OS after multivariate analysis.

\section{First-line treatment}

Treatment received was consistent with ENETS guidelines in 85 of the 104 included patients (82\%): 14/15 (93\%)

Published by Bioscientifica Ltd 
Table 1 Characteristics of patients with metastatic pancreatic neuroendocrine tumors in accordance with the three groups defined in ENETS 2016 guidelines: Group 1 (complete resection), Group 2 (watch and wait or somatostatin analogs) and Group 3 (cytotoxic chemotherapy).

\begin{tabular}{|c|c|c|c|c|}
\hline & $\begin{array}{c}\text { Group 1 } \\
(n=15(15 \%))\end{array}$ & $\begin{array}{c}\text { Group 2 } \\
(n=16(15 \%))\end{array}$ & $\begin{array}{c}\text { Group 3 } \\
(n=73(70 \%))\end{array}$ & $\begin{array}{c}\text { All patients } \\
(n=104(100 \%))\end{array}$ \\
\hline Age, years, median (range) & $55(27-67)$ & $67(45-89)$ & $58(24-84)$ & $59(24-84)$ \\
\hline Gender, female, $n(\%)$ & $10(67 \%)$ & $8(50 \%)$ & $39(53 \%)$ & $57(55 \%)$ \\
\hline \multicolumn{5}{|l|}{ ECOG performance status, $n(\%)$} \\
\hline $0-1$ & $13(100 \%)$ & $13(93 \%)$ & $63(95 \%)$ & $89(96 \%)$ \\
\hline$\geq 2$ & $0(0 \%)$ & $1(7 \%)$ & $3(5 \%)$ & $4(4 \%)$ \\
\hline Not available & 2 & 2 & 7 & 11 \\
\hline \multicolumn{5}{|l|}{ Localization of primary tumor, $n(\%)$} \\
\hline Head & $1(7 \%)$ & $4(25 \%)$ & $31(42 \%)$ & $36(35 \%)$ \\
\hline Body & $4(27 \%)$ & $6(37.5 \%)$ & $20(27 \%)$ & $30(29 \%)$ \\
\hline Tail & $10(67 \%)$ & $6(37.5 \%)$ & $22(30 \%)$ & $38(36 \%)$ \\
\hline Functioning tumors, $n(\%)$ & $7(47 \%)$ & $1(7 \%)$ & $8(11 \%)$ & $16(15 \%)$ \\
\hline \multicolumn{5}{|l|}{ Number of metastatic sites, $n(\%)$} \\
\hline 1 & $14(93 \%)$ & $15(94 \%)$ & $48(66 \%)$ & $77(74 \%)$ \\
\hline$\geq 2$ & $1(7 \%)$ & $1(6 \%)$ & $25(34 \%)$ & $27(26 \%)$ \\
\hline \multicolumn{5}{|l|}{ Location of metastatic sites, $n(\%)$} \\
\hline Liver & $15(100 \%)$ & $14(88 \%)$ & $69(95 \%)$ & $98(94 \%)$ \\
\hline Bone & $0(0 \%)$ & $0(0 \%)$ & $13(18 \%)$ & $13(12 \%)$ \\
\hline Lung & $0(0 \%)$ & $1(6 \%)$ & $4(5 \%)$ & $5(5 \%)$ \\
\hline Distant nodes & $1(7 \%)$ & $0(0 \%)$ & $9(12 \%)$ & $10(10 \%)$ \\
\hline Othera & $0(0 \%)$ & $1(6 \%)$ & $5(7 \%)$ & $6(6 \%)$ \\
\hline \multicolumn{5}{|l|}{ Liver tumor volume, $n(\%)$} \\
\hline$<50 \%$ & $14(100 \%)$ & $16(100 \%)$ & $25(37 \%)$ & $55(56 \%)$ \\
\hline$\geq 50 \%$ & $0(0 \%)$ & $0(0 \%)$ & $43(63 \%)$ & $43(44 \%)$ \\
\hline Not available & 1 & 0 & 5 & 6 \\
\hline \multicolumn{5}{|l|}{ Tumor growth rate, $n(\%)$} \\
\hline Unknownb & $4(27 \%)$ & $3(19 \%)$ & $32(44 \%)$ & $21(20 \%)$ \\
\hline Progressive disease & $5(33 \%)$ & $0(0 \%)$ & $29(40 \%)$ & $34(33 \%)$ \\
\hline Stable disease & $2(13 \%)$ & $8(50 \%)$ & $0(0 \%)$ & $10(10 \%)$ \\
\hline Not available & $4(27 \%)$ & $5(31 \%)$ & $32(44 \%)$ & $39(37 \%)$ \\
\hline Uptake on Octreoscan, $n(\%)$ & $11 / 12(92 \%)$ & $14 / 15(93 \%)$ & $49 / 60(82 \%)$ & $74 / 87(85 \%)$ \\
\hline Uptake on TEP FDG, $n(\%)$ & $2 / 4(50 \%)$ & $2 / 4(50 \%)$ & $22 / 24(92 \%)$ & $26 / 32(81 \%)$ \\
\hline Chromagranin A (xULN), median (range) & $1(1-8)$ & $2(1-14)$ & $2(1-160)$ & $2(1-160)$ \\
\hline Elevated ( $\geq 2$ ULN) chromogranin A, $n(\%)$ & $3 / 10(30 \%)$ & & $32 / 56(57 \%)$ & $39 / 85(46)$ \\
\hline Elevated PAL $(>N), n(\%)$ & $0 / 8(0 \%)$ & $2 / 13(15 \%)$ & $13 / 60(22 \%)$ & $15 / 81(19 \%)$ \\
\hline \multicolumn{5}{|l|}{ Tumor grading, $n(\%)$} \\
\hline Grade 1 & $0(0 \%)$ & $3(19 \%)$ & $6(8 \%)$ & $9(9 \%)$ \\
\hline Grade 2 & $15(100 \%)$ & $13(81 \%)$ & $52(71 \%)$ & $80(77 \%)$ \\
\hline Grade 3 & $0(0 \%)$ & $0(0 \%)$ & $15(21 \%)$ & $15(14 \%)$ \\
\hline Ki67 (\%), median (range) & $7(3-20)$ & $3(1-10)$ & $10(1-60)$ & $10(1-60)$ \\
\hline Death, $n(\%)$ & $1(7 \%)$ & $1(6 \%)$ & $29(40 \%)$ & $31(30 \%)$ \\
\hline Median $(95 \% \mathrm{Cl})$ overall survival in months & Not reached & Not reached & $64(35-93)$ & $104(65-143)$ \\
\hline Surgery of the primary tumor, $n(\%)$ & $15(100 \%)$ & $14(88 \%)$ & $37(51 \%)$ & $66(64 \%)$ \\
\hline \multicolumn{5}{|l|}{ Type of first-line treatment } \\
\hline RFA or surgery of liver metastases & $14(93 \%)$ & $0(0 \%)$ & $0(0 \%)$ & $14(13 \%)$ \\
\hline TAE/TACE & $0(0 \%)$ & $0(0 \%)$ & $4(5 \%)$ & $4(4 \%)$ \\
\hline Watch and wait & $0(0 \%)$ & $6(37 \%)$ & $1(1 \%)$ & $7(7 \%)$ \\
\hline Somatostatin analogs & $1(7 \%)$ & $10(63 \%)$ & $4(6 \%)$ & $15(14 \%)$ \\
\hline Everolimus & $0(0 \%)$ & $0(0 \%)$ & $10(14 \%)$ & $10(10 \%)$ \\
\hline Cytotoxic chemotherapy & $0(0 \%)$ & $0(0 \%)$ & $54(74 \%)$ & $54(52 \%)$ \\
\hline Median number of lines during the course of the disease & $5(1-9)$ & $2(1-5)$ & $3(1-11)$ & $3(1-11)$ \\
\hline Median number of lines received among dead patients & $7(7-7)$ & $1(1-1)$ & $3(1-11)$ & $3(1-11)$ \\
\hline
\end{tabular}

aOther: peritoneum $(n=4)$, thyroid gland $(n=1)$, epiglottis $(n=1)$, subcutaneous $(n=1)$. ${ }^{b}$ Treatment initiated before tumor slope assessment by CT scan or MRI.

PAL, alkaline phosphatase; RFA, radiofrequency ablation; TACE, transarterial chemoembolization; TAE, transarterial embolization; TEP FDG, 18F-fluorodeoxyglucose positron emission tomography.

http://erc.endocrinology-journals.org DOI: $10.1530 /$ ERC-16-0464
๑ 2017 Society for Endocrinology Printed in Great Britain
Published by Bioscientifica Ltd. 
Table 2 Characteristics of patients in Group 3, between NET-G2 and NTE-G3.

\begin{tabular}{|c|c|c|c|}
\hline & NET-G2 $(n=52)$ & NET-G3 $(n=15)$ & $\boldsymbol{P}$ \\
\hline $\begin{array}{l}\text { Functioning tumors, } \\
n(\%)\end{array}$ & $5(10 \%)$ & $2^{a}(13 \%)$ & 0.68 \\
\hline $\begin{array}{l}\text { Number of metastatic } \\
\text { sites, } n(\%)\end{array}$ & & & 0.61 \\
\hline 1 & $35(67 \%)$ & $9(60 \%)$ & \\
\hline$\geq 2$ & $17(33 \%)$ & $6(40 \%)$ & \\
\hline Liver tumor volume & & & 0.79 \\
\hline$<50 \%$ & $30(64 \%)$ & $9(60 \%)$ & \\
\hline$>50 \%$ & $17(36 \%)$ & $6(40 \%)$ & \\
\hline $\begin{array}{l}\text { Tumor growth rate, } \\
n(\%)\end{array}$ & & & 0.16 \\
\hline Unknown b & $21(40 \%)$ & $8(53 \%)$ & \\
\hline Progressive disease & $24(46 \%)$ & $3(20 \%)$ & \\
\hline Stable disease & $0(0 \%)$ & $0(0 \%)$ & \\
\hline Not available & $7(14 \%)$ & $4(27 \%)$ & \\
\hline Uptake on Octreoscan & $38 / 43(88 \%)$ & $5 / 11(46 \%)$ & 0.002 \\
\hline Uptake on TEP FDG & $18 / 19(95 \%)$ & $3 / 3(100 \%)$ & 0.68 \\
\hline Elevated (>2 ULN) CgA & $24(59 \%)$ & $6(55 \%)$ & 0.81 \\
\hline $\begin{array}{l}\text { Median }(95 \% \mathrm{CI}) \\
\text { overall survival in } \\
\text { months }\end{array}$ & $98(57-138)$ & $27(0.1-61)$ & 0.003 \\
\hline
\end{tabular}

aOne Zollinger Elison Syndrome and one insulinoma. ${ }^{\mathrm{b}}$ Treatment initiated before tumor slope assessment by CT scan or MRI.

CgA, chromogranin A; TEP FDG, 18F-fluorodeoxyglucose positron emission tomography.

of those in Group 1, 16/16 (100\%) of those in Group 2 and $54 / 73(74 \%)$ of those in Group 3. One patient in Group 1 declined proposed liver metastases surgery and subsequently received SSA. Among patients of Group 2, 10 (63\%) received SSA upfront and 6 (37\%) were followed (watch-and-wait strategy). Thus, 54 patients of Group 3 received cytotoxic chemotherapy which was temozolomide based $(n=28,52 \%$ of those who received cytotoxic chemotherapy) or dacarbazine based $(n=2$, $4 \%)$, streptozotocin based ( $n=14,26 \%)$, oxaliplatin based $(n=6,11 \%)$ or cisplatin etoposide $(n=4,8 \%)$. Among the 19 patients of Group 3 who did not receive chemotherapy,
4 patients underwent liver embolization ( 2 functioning mP-NET and 2 patients with liver metastases alone); 10 patients received everolimus (patient choice $n=2$, less aggressive disease $n=2$, inclusion in a clinical trial $n=4$, anti-secretory effect $n=2$ patients with insulinoma); 5 patients were treated by SSA $(n=4)$ or watch-andwait strategy $(n=1)$ because of comorbidities (ongoing treatment for another cancer $n=2$, elderly patient with severe comorbidities $n=2$, or patient refusal $n=1$ ). No patient received sunitinib or PRRT as first-line treatment.

\section{All treatments received during the course of the disease}

During the course of the disease, 30/67 (45\%) patients with synchronous mP-NET underwent surgery of their primary tumor. In this group, median OS was 130 (95\% CI: 71-188) months, which was longer than that found for the 37 patients who did not undergo primary tumor surgery (OS: 64, 95\% CI: 23-104 months). Patients who underwent this surgery more frequently had a tumor in the pancreatic tail $(60 \% ; P=0.01)$, a low liver tumor volume $(83 \% ; P=0.005)$ and normal CgA levels $(P=0.02$; Table 4$)$.

Patients received a median 3 (range: 1-11) different lines of treatment. Among the 31 deceased patients, $58 \%$ received less than 4 different lines of treatment (firstline only, $n=2,6 \%$; second line, $n=9,29 \%$; third line, $n=7$, $23 \%)$. Nine (30\%) patients received 4-6 lines of treatment, and 4 (13\%) patients more than 6 lines.

The 104 patients were treated with 306 different systemic treatments. Among them, 99 intravenous and 44 oral chemotherapies were given; among targeted therapy, 54 and 23 received everolimus and/or sunitinib; PRRT was given to 16 patients and $75 \%$ of them received it after two other treatments lines (Table 5). Among patients treated by SSA, almost all discontinued SSA because of the occurrence of progressive disease. Reasons for discontinuation and
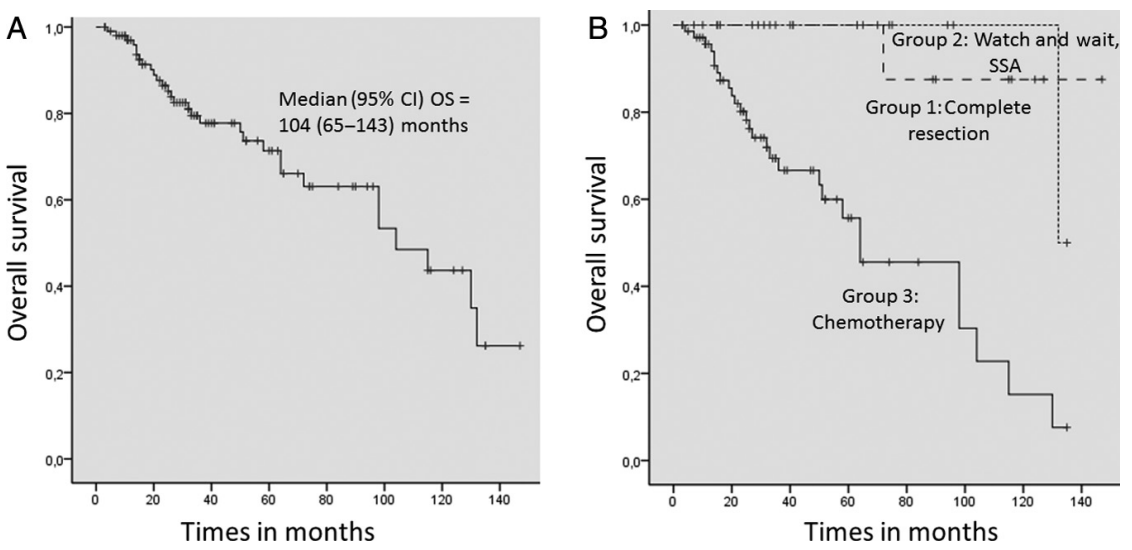

Figure 1

Overall survival (OS) for the total population of metastatic pancreatic neuroendocrine tumors (A) and according to treatment groups defined by ENETS 2016 guidelines (B). SSA, somatostatin analogs. 

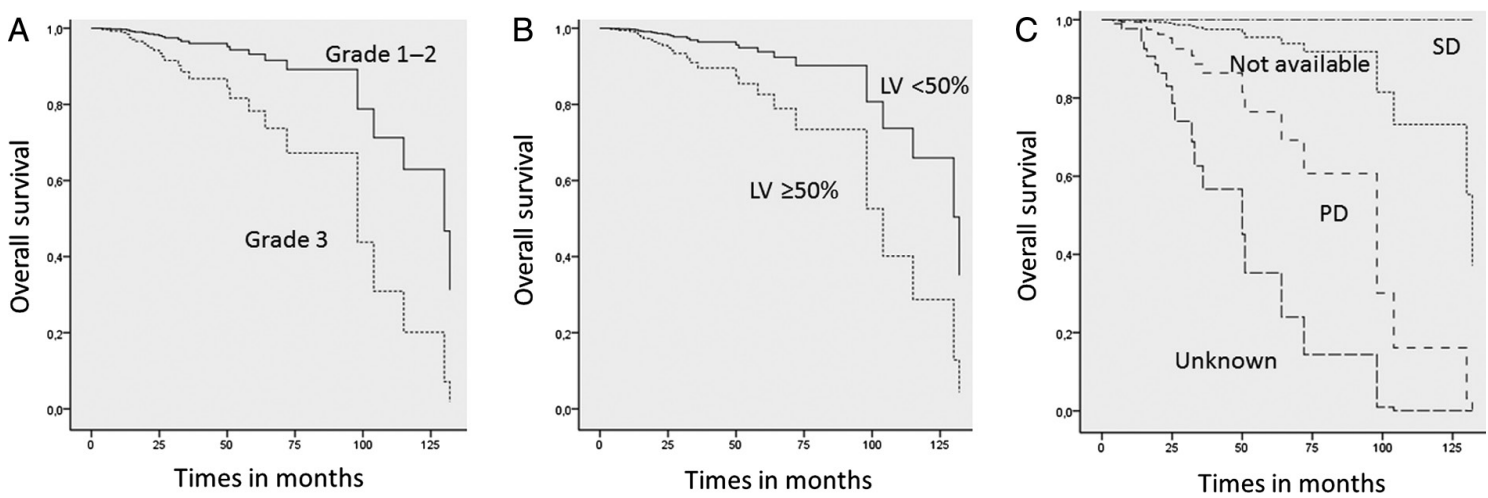

Figure 2

Overall survival (multivariate analysis) of patients with metastatic pancreatic neuroendocrine tumors according to grades (A), tumor liver volume (LV) (B) and tumor growth rate (C). PD, progressive disease; SD, stable disease.

effectiveness were similar between intravenous and oral chemotherapies. Sunitinib was given in later lines than everolimus, and the median duration of treatment was shorter. Sunitinib was discontinued because of toxicities $(12 \%)$ or patient choice $(22 \%)$ more often than was everolimus ( $6 \%$ and $12 \%$, respectively); for both, the objective response was lower than 10\% (Table 5).

\section{Discussion}

We report here the management of mP-NETs according to treatment groups defined in the ENETS 2016 guidelines (Pavel et al. 2016). This retrospective study assessing more than 100 patients has several strengths. Firstly, the population is well characterized: functioning status, localization of primary tumor, number and location of metastatic sites, tumor grading and type of treatments were available for all patients (and liver involvement for all but 6); the two pathologists ( $\mathrm{V} \mathrm{H}$ and J-Y S) are members of the TENpath Network and all NET-G3 were reviewed; over three-quarters of patients had Octreoscan data and CgA levels at diagnosis of mP-NETs; for nearly two-thirds of patients, the TGR was available. Thus, it was also possible to study the prognostic factors in a homogeneous population of well-differentiated mP-NETs. Secondly, the management of mP-NETs of this population benefited from the same organization of care since the start of the period considered (2004), which requires that all treatments must be discussed within the setting of multidisciplinary tumor meeting. Furthermore, the study center is an ENETS center of excellence, and the team of physicians has been the same for more than 15 years.

We show for the first time the distribution within these three treatment groups described by ENETS (Pavel et al. 2016). Group 1 (complete resection if feasible) must be interpreted with caution owing to the retrospective nature of the study. This group is dependent on the amount of liver and extrahepatic metastases, which might be underestimated because 68Ga DOTATATE PET/CT was not routinely available in France during the study period. Therefore, in 2016, some patients could have been understaged and wrongly categorized into this group. More interesting is the high proportion of patients in Group 3 (who should have received chemotherapy, $70 \%$ ) in comparison with Group 2 (watch-and-wait or SSA, 15\%). Thus, only a sixth of the patients were in the population defined in the CLARINET study (Caplin et al. 2014). This proportion may reflect a population bias in our tertiary center to which patients with more aggressive disease are more likely to be referred. There is evidence, however, that this is not the case; OS was very long (median 104 months from diagnosis of mP-NETs and $62 \% 5$-year OS). OS is longer than that in a recent study of 92 patients with unresectable/metastatic P-NET (60-month median OS and 51\% 5-year OS) (Berdelou et al. 2016). Furthermore, this included a minority of welldifferentiated grade 3 NET (NET-G3), that we chose to include in Group 3. We found similar characteristics for NET-G2 and NET-G3, except that NET-G3 had lower uptake on Octreoscan and were thus less eligible for PRRT. Furthermore, we treated them with a similar cytotoxic chemotherapy (streptozotocin or temozolomidebased chemotherapy) as usually used in NET-G2. This management of NET-G3 is consistent with 2016 ENETS guidelines (Pavel et al. 2016) and with recent data showing that this subgroup (that will also be defined in the next WHO classification) appears to benefit from treatments given in NET-G2 rather than those given to patients with poorly neuroendocrine carcinoma (Heetfeld et al. 2015, Coriat et al. 2016). Thus, three-quarters of the patients

Published by Bioscientifica Ltd. 
Table 3 Prognostic factors of overall survival in 104 patients with metastatic pancreatic neuroendocrine tumors.

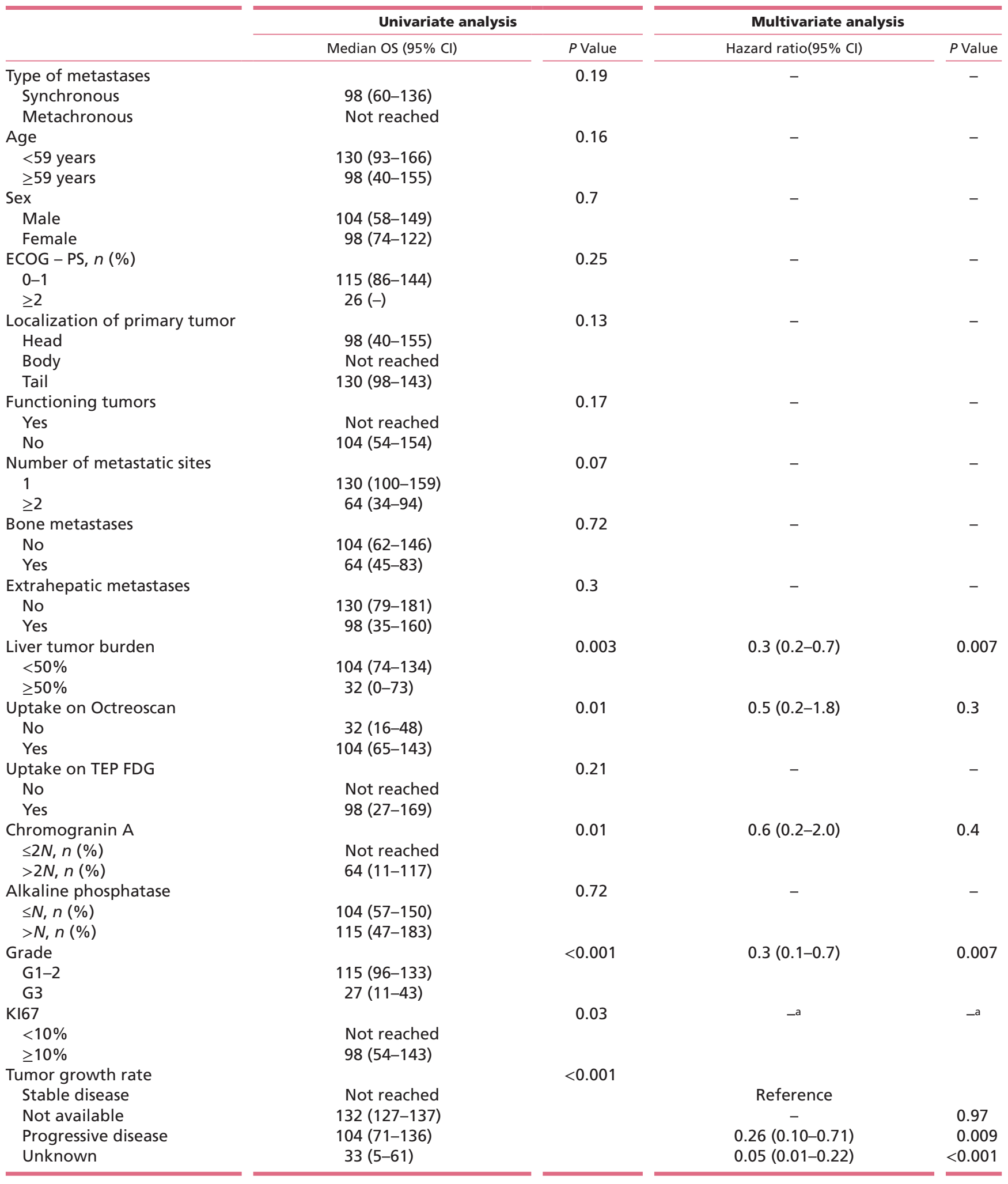

aGrade 3 but not Ki67 $>10 \%$ was used in the multivariate analysis because of the lower $P$ value in univariate analysis.

$\mathrm{Cl}$, confident interval; ECOG-PS, performance status; OS, overall survival; PAL, alkaline phosphatase; TEP FDG, 18F-fluorodeoxyglucose positron emission tomography. 
Table 4 Characteristics of the 67 patients with synchronous mP-NET in accordance with surgery of the primary tumor.

\begin{tabular}{|c|c|c|c|c|}
\hline & Surgery $(n=30)$ & No surgery $(n=37)$ & $\boldsymbol{P}$ & $\begin{array}{l}\text { All synchronous } \\
\text { mP-NET }(n=67)\end{array}$ \\
\hline \multicolumn{5}{|l|}{ Tumor location } \\
\hline Head & $6(20 \%)$ & $15(41 \%)$ & 0.01 & $21(31 \%)$ \\
\hline Body & $6(20 \%)$ & $13(35 \%)$ & & $19(28 \%)$ \\
\hline Tail & $18(60 \%)$ & $9(24 \%)$ & & $27(40 \%)$ \\
\hline \multicolumn{5}{|l|}{ Tumor grading } \\
\hline G1-G2 & $25(83 \%)$ & $32(87 \%)$ & 0.72 & $57(85 \%)$ \\
\hline G3 & $5(17 \%)$ & $5(13 \%)$ & & $10(15 \%)$ \\
\hline Liver tumor volume & & & & $41(64 \%)$ \\
\hline$<50 \%$ & $24(83 \%)$ & $17(49 \%)$ & 0.005 & $23(36 \%)$ \\
\hline$>50 \%$ & $5(17 \%)$ & $18(51 \%)$ & & \\
\hline Uptake on Octreoscan & $22 / 25(88 \%)$ & $23 / 28(82 \%)$ & 0.55 & $45 / 53$ \\
\hline Uptake on TEP FDG & $9 / 10(90 \%)$ & $9 / 9(100 \%)$ & 0.33 & $18 / 19$ \\
\hline Elevated (>2 ULN) CgA & $7 / 20(35 \%)$ & $20 / 29(69 \%)$ & 0.02 & $27 / 49(55 \%)$ \\
\hline Median $(95 \% \mathrm{Cl})$ overall survival & $130(71-188)$ & $64(23-104)$ & 0.04 & $98(46-150)$ \\
\hline
\end{tabular}

CgA, chromogranin A; Cl, confidence interval; TEP FDG, 18F-fluorodeoxyglucose positron emission tomography.

required first-line chemotherapy (Group 3), which was $60 \%$ in the study reported by Berdelou et al. (2016). This indicates the need for clinical trials to define the best chemotherapy regimen: intravenous or oral agents; streptozotocin/temozolomide-based or oxaliplatin-based chemotherapy; impact of MGMT status on this choice
(Dussol et al. 2015); association with bevacizumab (Ducreux et al. 2014).

These three groups clearly associated with different OS, which was much worse in Group 3 than in Groups 1 and 2. OS was slightly better in Group 1 than in Group 2 (non-significant), which could be explained

Table 5 Therapeutic management and effectiveness of systemic treatments in metastatic pancreatic neuroendocrine tumors.

\begin{tabular}{|c|c|c|c|c|c|c|}
\hline & SSA & $\begin{array}{l}\text { Intravenous } \\
\text { chemotherapy }\end{array}$ & $\begin{array}{c}\text { Oral } \\
\text { chemotherapy }\end{array}$ & Everolimus & Sunitinib & PRRT \\
\hline Number of treatments given & 70 & 99 & 44 & 54 & 23 & 16 \\
\hline \multicolumn{7}{|l|}{ Lines of systemic treatments } \\
\hline 1 & $27(39)$ & $36(37)$ & $20(46)$ & $12(22)$ & $0(0)$ & $0(0)$ \\
\hline 2 & $23(33)$ & $22(22)$ & $8(18)$ & $19(35)$ & $6(26)$ & $4(25)$ \\
\hline 3 & $6(8)$ & $17(17)$ & $5(11)$ & $14(26)$ & $6(26)$ & $6(37.5)$ \\
\hline$\geq 4$ & $14(20)$ & $24(24)$ & $11(25)$ & $9(17)$ & $11(48)$ & $6(37.5)$ \\
\hline \multicolumn{7}{|l|}{ PD (RECIST) before treatment } \\
\hline Yes & $26(37)$ & $61(62)$ & $32(73)$ & $42(78)$ & $18(78)$ & $13(82)$ \\
\hline No & $30(43)$ & $7(7)$ & $1(2)$ & $1(2)$ & $4(17)$ & $0(0)$ \\
\hline Unknowna & $3(4)$ & $21(21)$ & $9(21)$ & $6(11)$ & $0(0)$ & $0(0)$ \\
\hline Not available & $11(16)$ & $10(10)$ & $2(4)$ & $5(9)$ & $1(4)$ & $3(18)$ \\
\hline Median (range) duration of treatment in month & $8(1-133)$ & $3(1-28)$ & $3(1-17)$ & $4(0-85)$ & $2(0-86)$ & $5(1-7)$ \\
\hline \multicolumn{7}{|l|}{ Reason for discontinuation, $n(\%)$} \\
\hline Radiological PD (RECIST) & $39(56)$ & $28(28)$ & $6(14)$ & $32(59)$ & $10(44)$ & $2(12)$ \\
\hline Clinical progression (but not RECIST) & $3(4)$ & $6(6)$ & $2(4)$ & $1(2)$ & $3(13)$ & $0(0)$ \\
\hline Scheduled & $0(0)$ & $51(51)$ & $29(65)$ & $8(15)$ & $2(9)$ & $14(88)$ \\
\hline Grade $3-5$ toxicity & $0(0)$ & $9(9)$ & $4(9)$ & $3(6)$ & $3(12)$ & $0(0)$ \\
\hline Patient choice ${ }^{b}$ & $2(3)$ & $0(0)$ & $0(0)$ & $7(12)$ & $5(22)$ & $0(0)$ \\
\hline Not available or still on treatment & $26(37)$ & $5(5)$ & $3(7)$ & $3(6)$ & $0(0)$ & $0(0)$ \\
\hline \multicolumn{7}{|l|}{ Best response, $n(\%)$} \\
\hline Objective response & $3(4)$ & $13(13)$ & $8(18)$ & $3(6)$ & $1(4)$ & $2(12)$ \\
\hline Stable disease & $45(64)$ & $53(53)$ & $26(59)$ & $32(59)$ & $10(44)$ & $8(50)$ \\
\hline Progressive disease & $12(17)$ & $25(25)$ & $6(14)$ & $12(22)$ & $7(30)$ & $2(12)$ \\
\hline Not availablec & $10(14)$ & $8(8)$ & $4(9)$ & $7(13)$ & $5(22)$ & $4(25)$ \\
\hline
\end{tabular}

aTreatment initiated before tumor slope assessment by CT scan or MRI. b Mostly because occurrence of grade 1 or 2 toxicity. cPatient on treatment or for whom radiological response was not evaluated.

PD, progressive disease; PRRT, peptide receptor radionuclide treatment; SSA, somatostatin analogs. 
by tumor characteristics with higher median Ki67 and worse TGR in Group 1, the two main prognostic factors. More generally the prognostic factors found herein were those previously reported in more heterogeneous populations that combined different stages of P-NET or different types of primary (pancreas and gastrointestinal NET) or different differentiation status (well and poorly) (Pape et al. 2008a,b, Durante et al. 2009, Hentic et al. 2010, Panzuto et al. 2011). At the metastatic stage, we show that TGR appeared to be the most prognostic factor, followed by the proliferative index and liver tumor burden. However, it is clinically more pertinent to better characterize patients of Group 3, which includes patients with heterogeneous prognosis. In the latter, TGR was also the most significant prognostic factor; yet, we are not comfortable as clinicians to wait for the TGR in such patients (Durante et al. 2009, Panzuto et al. 2011). In the present study, nearly half the patients in Group 3 with high tumor burden or high-grade tumors were not assessed for TGR ('unknown') because they were treated upfront. In Group 3, the only other significant prognostic factor was tumor grading using a cut-off of $20 \% \mathrm{Ki} 67$ as opposed to $5 \%$ or $10 \%$. Thus, patients with a NET-G3 had a median OS of 27 months (98 months in Group 3 patients with NET-G1/G2). Other tools are therefore clearly needed to better stratify these patients to investigate whether we have time to prescribe several lines of treatments or not. As far as biological markers are concerned, $\mathrm{CgA}$ is known to be a surrogate marker of tumor burden (Baudin et al. 1998) and was associated with a worse OS in univariate analysis, but which was not significant in multivariate analysis. We did not find an association between ALP and OS, as suggested in other studies (Hauck et al. 2016, Onesti et al. 2016). A solution may come from the inclusion of molecular prognostic factors (Cwikla et al. 2015, Schmitt et al. 2016, Viudez et al. 2016) and/or the development of prognostic scores (Modlin et al. 2010, Viudez et al. 2016).

It is of note that although the study data were collected from 2004, there was a high degree of consistency between first-line treatments scheduled by 2016 ENETS guidelines and those given in real life. This is explained by the fact that all recommended first-line treatments (surgery, RFA, SSA, cytotoxic chemotherapy) were already available from the outset of data collection (Steinmuller et al. 2008). The consistency between recommendations and practice decreased to $75 \%$ in Group 3, but this was mainly due to 10 patients who received everolimus instead of chemotherapy as first-line treatment, either because of patient or physician choice (insulinoma, clinical trial). This strategy (everolimus first followed by chemotherapy at progression) is currently being explored by the SEQTOR study (NCT02246127).

This study also provides data for treatments given in mP-NET. As reported by Berdelou et al. (2016), we demonstrate that not all patients will benefit from all approved or recommended therapeutic options in mP-NET. In the present study, just over half of deceased patients received three lines or less. One goal of international research would be to design a prospective multicenter cohort with a very long follow-up to assess the main reasons for this, such as comorbidities, persistent treatment-related toxicity as recently suggested by Berdelou et al. (2016) or too rapid disease progressions in some high-grade mP-NET. We also found that surgery of the primary tumor, more often performed for tumor in the tail of the pancreas and for low-grade tumor and low tumor burden, is associated with a better OS. However, although consistent with other data (Durante et al. 2009), this study does not prove that surgery of the primary tumor should be performed for all synchronous mP-NET, as the data are subject to bias.

The present study has some limitations, including its retrospective design, accessibility and habits of treatments given in mP-NET. The full collection of imaging data was not reviewed and thus we were unable to investigate different cut-offs to assess the tumor liver volume. Concerning the median number of treatment lines, the values are underestimated as most patients are alive and will benefit from subsequent treatments. Moreover, the efficacy of everolimus (Yao et al. 2011), sunitinib (Raymond et al. 2011) or lanreotide (Caplin et al. 2014) has been recently reported in $\mathrm{mP}$-NET and we expect an increase in their use. This is even more the case for PRRT, which seems very promising in MP-NET, even if this is not as well proven as in midgut NET. All this means that the picture may change in the near future with a wider use of targeted therapies and PRRT.

In conclusion, most patients with mP-NET are in Group 3 and require chemotherapy upfront according to ENETS guidelines. We also report that most patients do not receive all available treatments, which points out, yet again, the critical importance of the selection of firstand second-line treatments. Thus, trials are warranted to improve first-line chemotherapy.

Supplementary data

This is linked to the online version of the paper at http://dx.doi.org/10.1530/ ERC-16-0464.

Published by Bioscientifica Ltd. 


\section{Declaration of interest}

Margaux Foulfoin (M F), Emmanuelle Graillot (E G), Mustapha Adham $(M A)$, Pascal Rousset (Pa R), Julien Forestier (J F), Valérie Hervieu $(V H)$, Philip Robinson (Ph R), Jean-Yves Scoazec (J-Y S), Catherine Lombard-Bohas (C L-B), Thomas Walter (T W). M F, E G, M A, Pa R, V H, Ph R, J-Y S declare that they have no conflicts of interest. J F: consultancies for Merck, Ipsen, Amgen, Celgen. C L-B: consultancies for Novartis, Ipsen, Keocyt, AAA, Sanofy. T W: consultancies for Novartis, Ipsen, Keocyt, Pfizer, Celgen.

\section{Funding}

This work did not receive any specific grant from any funding agency in the public, commercial or not-for-profit sector.

\section{Author contribution statement}

All of the authors have read the manuscript and agreed to its submission.

\section{References}

Baudin E, Gigliotti A, Ducreux M, Ropers J, Comoy E, Sabourin JC, Bidart JM, Cailleux AF, Bonacci R, Ruffie P, et al. 1998 Neuronspecific enolase and chromogranin A as markers of neuroendocrine tumours. British Journal of Cancer $\mathbf{7 8}$ 1102-1107. (doi:10.1038/ bjc.1998.635)

Berdelou A, Boige V, Arfi-Rouche J, Malka D, Ederhy S, Izzedine H, Leboulleux S, Chougnet CN, Burtin P, De Baere T, et al. 2016 All patients with a pancreatic neuroendocrine tumour (pNET) will not benefit from all approved or recommended therapeutic options: a real life retrospective study. Neuroendocrinology [in press]. (doi:10.1159/000446988)

Caplin ME, Pavel M, Cwikla JB, Phan AT, Raderer M, Sedlackova E, Cadiot G, Wolin EM, Capdevila J, Wall L, et al. 2014 Lanreotide in metastatic enteropancreatic neuroendocrine tumors. New England Journal of Medicine 371 224-233. (doi:10.1056/NEJMoa1316158)

Coriat R, Walter T, Terris B, Couvelard A \& Ruszniewski P 2016 Gastroenteropancreatic well-differentiated grade 3 neuroendocrine tumors: review and position statement. Oncologist 21 1191-1199. (doi:10.1634/theoncologist.2015-0476)

Cwikla JB, Bodei L, Kolasinska-Cwikla A, Sankowski A, Modlin IM \& Kidd M 2015 Circulating transcript analysis (NETest) in GEP-NETs treated with somatostatin analogs defines therapy. Journal of Clinical Endocrinology and Metabolism 100 E1437-E1445. (doi:10.1210/ jc.2015-2792)

Ducreux M, Dahan L, Smith D, O'Toole D, Lepere C, Dromain C, Vilgrain V, Baudin E, Lombard-Bohas C, Scoazec JY, et al. 2014 Bevacizumab combined with 5-FU/streptozocin in patients with progressive metastatic well-differentiated pancreatic endocrine tumours (BETTER trial) - a phase II non-randomised trial. European Journal of Cancer 50 3098-3106. (doi:10.1016/j.ejca.2014.10.002)

Durante C, Boukheris H, Dromain C, Duvillard P, Leboulleux S, Elias D, de Baere T, Malka D, Lumbroso J, Guigay J, et al. 2009 Prognostic factors influencing survival from metastatic (stage IV) gastroenteropancreatic well-differentiated endocrine carcinoma. Endocrine-Related Cancer 16 585-597. (doi:10.1677/ERC-08-0301)

Dussol AS, Joly MO, Vercherat C, Forestier J, Hervieu V, Scoazec JY, Lombard-Bohas C \& Walter T 2015 Gemcitabine and oxaliplatin or alkylating agents for neuroendocrine tumors: Comparison of efficacy and search for predictive factors guiding treatment choice. Cancer 121 3428-3434. (doi:10.1002/cncr.29517)

Hauck L, Bitzer M, Malek N \& Plentz RR 2016 Subgroup analysis of patients with G2 gastroenteropancreatic neuroendocrine tumors.
Scandinavian Journal of Gastroenterology 51 55-59. (doi:10.3109/00365 521.2015.1064994)

Heetfeld M, Chougnet CN, Olsen IH, Rinke A, Borbath I, Crespo G, Barriuso J, Pavel M, O'Toole D \& Walter T 2015 Characteristics and treatment of patients with G3 gastroenteropancreatic neuroendocrine neoplasms. Endocrine-Related Cancer 22 657-664. (doi:10.1530/ERC-15-0119)

Hentic O, Couvelard A, Rebours V, Zappa M, Dokmak S, Hammel P, Maire F, O'Toole D, Levy P, Sauvanet A, et al. 2010 Ki-67 index, tumor differentiation, and extent of liver involvement are independent prognostic factors in patients with liver metastases of digestive endocrine carcinomas. Endocrine-Related Cancer 18 51-59. (doi:10.1677/ERC-09-0319)

Modlin IM, Gustafsson BI, Pavel M, Svejda B, Lawrence B \& Kidd M 2010 A nomogram to assess small-intestinal neuroendocrine tumor ('carcinoid') survival. Neuroendocrinology 92 143-157. (doi:10.1159/000319784)

Onesti JK, Shirley LA, Saunders ND, Davidson GW, Dillhoff ME, Khabiri H, Guy GE, Dowell JD, Schmidt CR, Shah MH, et al. 2016 Elevated alkaline phosphatase prior to transarterial chemoembolization for neuroendocrine tumors predicts worse outcomes. Journal of Gastrointestinal Surgery 20 580-586. (doi:10.1007/s11605-015-2998-6)

Panzuto F, Boninsegna L, Fazio N, Campana D, Pia Brizzi M, Capurso G, Scarpa A, De Braud F, Dogliotti L, Tomassetti P, et al. 2011 Metastatic and locally advanced pancreatic endocrine carcinomas: analysis of factors associated with disease progression. Journal of Clinical Oncology 29 2372-2377. (doi:10.1200/JCO.2010.33.0688)

Pape UF, Berndt U, Muller-Nordhorn J, Bohmig M, Roll S, Koch M, Willich SN \& Wiedenmann B 2008a Prognostic factors of long-term outcome in gastroenteropancreatic neuroendocrine tumours. Endocrine-Related Cancer 15 1083-1097. (doi:10.1677/ERC-08-0017)

Pape UF, Jann H, Muller-Nordhorn J, Bockelbrink A, Berndt U, Willich SN, Koch M, Rocken C, Rindi G \& Wiedenmann B 2008b Prognostic relevance of a novel TNM classification system for upper gastroenteropancreatic neuroendocrine tumors. Cancer 113 256-265. (doi:10.1002/cncr.23549)

Pavel M, O'Toole D, Costa F, Capdevila J, Gross D, Kianmanesh R, Krenning E, Knigge U, Salazar R, Pape UF, et al. 2016 ENETS consensus guidelines update for the management of distant metastatic disease of intestinal, pancreatic, bronchial neuroendocrine neoplasms (NEN) and NEN of unknown primary site. Neuroendocrinology 103 172-185. (doi:10.1159/000443167)

Raymond E, Dahan L, Raoul JL, Bang YJ, Borbath I, Lombard-Bohas C, Valle J, Metrakos P, Smith D, Vinik A, et al. 2011 Sunitinib malate for the treatment of pancreatic neuroendocrine tumors. New England Journal of Medicine 364 501-513. (doi:10.1056/ NEJMoa1003825)

Schmitt AM, Marinoni I, Blank A \& Perren A 2016 New genetics and genomic data on pancreatic neuroendocrine tumors: implications for diagnosis, treatment, and targeted therapies. Endocrine Pathology $\mathbf{2 7}$ 200-204. (doi:10.1007/s12022-016-9447-2)

Scoazec JY, Couvelard A, Monges G, Guyetant S, Bisot-Locard S, Parot X \& Lepage C 2016 Professional practices and diagnostic issues in neuroendocrine tumour pathology: results of a prospective one-year survey among french pathologists (the PRONET study). Neuroendocrinology [in press]. (doi:10.1159/000448431)

Steinmuller T, Kianmanesh R, Falconi M, Scarpa A, Taal B, Kwekkeboom DJ, Lopes JM, Perren A, Nikou G, Yao J, et al. 2008 Consensus guidelines for the management of patients with liver metastases from digestive (neuro)endocrine tumors: foregut, midgut, hindgut, and unknown primary. Neuroendocrinology 87 47-62. (doi:10.1159/000111037)

Viudez A, Carvalho FL, Maleki Z, Zahurak M, Laheru D, Stark A, Azad NZ, Wolfgang CL, Baylin S, Herman JG, et al. 2016 A new immunohistochemistry prognostic score (IPS) for recurrence and 
survival in resected pancreatic neuroendocrine tumors (PanNET). Oncotarget 7 24950-24961. (doi:10.18632/oncotarget.7436)

Yao JC, Hassan M, Phan A, Dagohoy C, Leary C, Mares JE, Abdalla EK, Fleming JB, Vauthey JN, Rashid A, et al. 2008 One hundred years after 'carcinoid': epidemiology of and prognostic factors for neuroendocrine tumors in 35,825 cases in the United States.
Journal of Clinical Oncology 26 3063-3072. (doi:10.1200/ JCO.2007.15.4377)

Yao JC, Shah MH, Ito T, Bohas CL, Wolin EM, Van Cutsem E, Hobday TJ, Okusaka T, Capdevila J, de Vries EG, et al. 2011 Everolimus for advanced pancreatic neuroendocrine tumors. New England Journal of Medicine 364 514-523. (doi:10.1056/NEJMoa1009290)

Received in final form 7 December 2016

Accepted 13 December 2016

Accepted Preprint published online 13 December 2016
Published by Bioscientifica Ltd. 